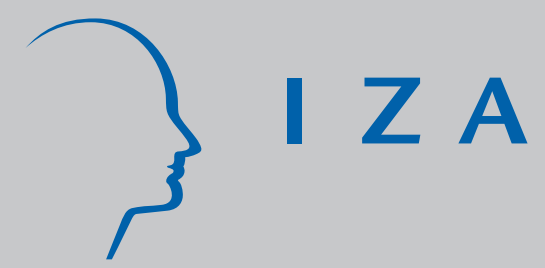

IZA DP No. 7302

Does Easy Start-Up Formation Hamper Incumbents' R\&D Investment? A Theoretical and Empirical Analysis

Luca Colombo

Herbert Dawid

Mariacristina Piva

Marco Vivarelli

March 2013 


\title{
Does Easy Start-Up Formation Hamper Incumbents' R\&D Investment? A Theoretical and Empirical Analysis
}

\author{
Luca Colombo \\ Università Cattolica del Sacro Cuore \\ Herbert Dawid \\ Bielefeld University \\ Mariacristina Piva \\ Università Cattolica del Sacro Cuore \\ Marco Vivarelli \\ Università Cattolica del Sacro Cuore, \\ SPRU-University of Sussex and IZA
}
Discussion Paper No. 7302
March 2013

\author{
IZA \\ P.O. Box 7240 \\ 53072 Bonn \\ Germany \\ Phone: +49-228-3894-0 \\ Fax: +49-228-3894-180 \\ E-mail: iza@iza.org
}

\begin{abstract}
Any opinions expressed here are those of the author(s) and not those of IZA. Research published in this series may include views on policy, but the institute itself takes no institutional policy positions. The IZA research network is committed to the IZA Guiding Principles of Research Integrity.

The Institute for the Study of Labor (IZA) in Bonn is a local and virtual international research center and a place of communication between science, politics and business. IZA is an independent nonprofit organization supported by Deutsche Post Foundation. The center is associated with the University of Bonn and offers a stimulating research environment through its international network, workshops and conferences, data service, project support, research visits and doctoral program. IZA engages in (i) original and internationally competitive research in all fields of labor economics, (ii) development of policy concepts, and (iii) dissemination of research results and concepts to the interested public.
\end{abstract}

IZA Discussion Papers often represent preliminary work and are circulated to encourage discussion. Citation of such a paper should account for its provisional character. A revised version may be available directly from the author. 


\section{ABSTRACT}

\section{Does Easy Start-Up Formation Hamper Incumbents' R\&D Investment? A Theoretical and Empirical Analysis}

This paper investigates, both theoretically and empirically, the implications that complementary assets needed for the formation of start-ups - proxied by the ease of access to financial resources - have on the innovative efforts of incumbent firms. In particular, we develop a theoretical model, highlighting a strategic incentive effect by which the innovative efforts of incumbent firms are decreasing in the availability of the complementary assets needed for the creation of a start- up. The empirical relevance of this effect is investigated by using firm level data drawn from the third Italian Community Innovation Survey covering the period 1998-2000. The results of our empirical analysis support our theory-based insights.

JEL Classification: $\quad$ O31, L26

Keywords: $\quad$ R\&D, innovation, start-up, complementary assets

Corresponding author:

Marco Vivarelli

Università Cattolica del Sacro Cuore

Facoltà di Economia

via Emilia Parmense 84

29100 Piacenza

Italy

E-mail: marco.vivarelli@unicatt.it 


\section{Introduction}

It is often argued that the knowledge embodied in firms' employees is an important vehicle for the diffusion of technology. Indeed, there is broad empirical evidence showing that technological change in many industries is fostered by the entry of start-ups created by former employees of incumbent firms (see, e.g., Klepper and Sleeper, 2005, and Klepper, 2010). In this context, to the extent that the knowledge of 'key' employees can not be fully appropriated by an incumbent (for instance, because it is to some extent tacit knowledge $)^{1}$, the threat of creating a new firm may distort incumbents' incentives to invest in innovative activities. The effects of employee mobility on firms' innovative efforts has been investigated in the literature. In particular, Franco and Filson (2006) develop a dynamic industry model with endogenous R\&D effort in which spin-out firms can be started by former employees of incumbents. Using data from the disk drive industry, they also show that taking this channel into account helps explaining the pattern of start-ups formation and firms survival. Similarly, the theoretical work by Gersbach and Schmutzler (2003a,b) points to the importance of worker mobility for firms' incentives to invest in R\&D. Indeed, they show that R\&D incentives under price competition are larger than under quantity competition in the presence of endogenous spillovers stemming from worker mobility, while the converse is true when worker mobility is neglected. As in our model, in these papers the innovation effort of firms is endogenous. However, our main focus here is on the effects of the availability of complementary assets for incumbents' R\&D investment, an issue that has not been considered by this literature.

Starting with Teece (1986), a number of authors have pointed out the importance of different types of complementary assets for the creation of new firms ${ }^{2}$. Numerous examples of complementary assets, which are critical for the successful commercialization of new technologies, have been given in the literature. These include expertise and infrastructure for product development, manufacturing, legal, sales, distribution and customer service activities, as well as access to capital markets (see, e.g. Rothaermel and Hill, 2005, Park and Steensma, 2012). An example of complementary asset that

\footnotetext{
${ }^{1}$ Zucker et Al. (1998), among others, have noted that the commercialization of innovative technologies (such as biotechnologies) is largely affected by the fact that the underlying relevant knowledge is tacit. From a theoretical perspective, Spulber (2012) investigates the role of tacit knowledge in the trade-off between entrepreneurship and technological transfer.

${ }^{2} \mathrm{~A}$ different stream of literature studies the potential creation of start-ups by focusing on ex-ante and ex-post contracting between an incumbent firm and a key employee in the presence of weak (or absent) property rights (see, among others, Anton and Yao, 1994, 1995, and Anand and Galetovic, 2000).
} 
has received most attention in the literature is the availability of financial resources and especially venture capital. For instance, the country reports of the European Innovation Scoreboard, published annually by the European Commission, regard early stage venture financing as a key indicator of the innovation potential of a region. These reports also show that the availability of such assets differs substantially between regions and present the reduction of barriers for accessing them as an objective of innovation policies. The effect that a reduction in the barriers to start-up formation might have on the R\&D investments of incumbent firms is however hardly understood and typically not considered in this discussion.

In this paper, we investigate the effects of complementary assets availability on the innovative efforts of incumbent firms and on the creation of start-ups by former employees. In our model an incumbent invests in R\&D generating new knowledge that is - at least partly - embodied in a key employee, who can possibly exploit it to create a new firm (a start-up). If the employee leaves the incumbent to create a start-up, the incumbent suffers a loss both because it cannot fully appropriate the returns from its $\mathrm{R} \& \mathrm{D}$ efforts (as it looses the share of knowledge remaining with the employee), and because a new competitor enters the industry. Eventually, the creation of a start-up is conditional on the availability of complementary assets and on the market demand the new start-up expects to face. The size of this demand is unknown when the firm decides about its R\&D investment, where an increase in investment shifts the distribution of demand realizations upwards. Before the key employee decides whether to form the start-up or not, the size of the demand for the potential start-up firm is revealed to her. The employee exits the firm and generates a start-up if her expected profit, which takes into account the costs of accessing the necessary complementary assets, exceeds her current income in the incumbent firm. When the needed complementary assets are easily available in the market, the value of the employee's outside option is large, which results in an increase in the ex-ante probability that a start-up is formed. Therefore, the incumbent's incentives to invest in $\mathrm{R} \& \mathrm{D}$ are reduced.

Our explanation of incumbents' innovative efforts as a function of the availability of complementary assets required for start-up formation builds essentially on a strategic argument: the more easily available complementary assets are, the higher the value of key employees outside option is and the lower the incentives of incumbents to invest in $R \& D$ are. Quite obviously, however, a number of other factors may be at work, possibly entirely offsetting the negative strategic effect outlined above. For instance, in a static perspective, non-compete clauses (or other covenants allowing the key employee to credibly commit ex ante not to leave the firm), as well as the design of schemes protecting intellectually property deriving from innovative activities, may be effective 
in allowing the incumbent to fully appropriate the benefits of its innovative efforts. However, clauses of this type are likely to be ineffective in several cases: indeed, there is a large literature stating that non-compete covenants are not always enforceable (see, e.g., Fallick et Al., 2006), and property rights over R\&D knowledge are often weak or absent (see, e.g., Anton and Yao, 1994, 1995). This is especially true when the knowledge acquired by key employees is to a large extent tacit, which is often the case in highly innovative sectors (see Zucker et Al., 1998, for the biotechnology industry, and Fallick et Al., 2006, for the computer industry).

Perhaps more important, in a dynamic perspective, start-up formation contributes to the creation of local clusters of firms, and there is robust evidence that the generation of knowledge in a cluster has positive knowledge externalities for the other firms in the cluster. Hence, the incumbent may benefit from the existence of a local cluster originated by the creation of start-ups ( see, e.g., Colombo et Al., 2012 for an analysis taking into account this effect). Jaffe et Al. (1993) and Audretsch and Feldman (1996), among others, show that technological spillovers across firms are likely to emerge when firms are geographically concentrated. Although we emphasize the role of knowledge externalities, it is well known that several other types of (positive and negative) externalities are relevant in clusters; see, e.g., Hanson (2001).

All these factors - that are likely to have a bite in practice - are neglected by our model, focusing entirely on the incentive effects stemming from the impact of the incumbent's decisions on the key employee's outside options. One may therefore question whether our arguments are of large practical relevance, or whether the tradeoff between the negative incentive effect we highlight and the direct effects of startup formation (favoring the emergence of industrial clusters, and generating positive externalities through local technological spillovers) should be resolved unambiguously in favor of the latter.

The second part of this paper addresses exactly this issue. After introducing in Section 2 a stylized model and deriving our main theoretical result, we bring the model to the data (in Section 3), to check whether the negative strategic relationship between the innovative efforts of established firms and the availability of complementary assets is of any empirical relevance. In particular, we investigate whether - ceteris paribus - there exists an inverse relationship between the availability of complementary assets (proxied in our analysis by the availability or lack of financial resources experienced by new entrants) and the R\&D expenditures by incumbents. ${ }^{3}$ The results of our em-

\footnotetext{
${ }^{3}$ As discussed above, the availability of the financial resources needed to start and develop a new company (be it in the form of bank loans, private equity, or venture capital) is a key factor in all industries to gain access to the complementary assets that are needed for start-up formation. Hence,
} 
pirical analysis (in Section 4) strongly support our theoretical claim that the R\&D intensity of incumbents is - ceteris paribus - negatively correlated with the availability of complementary assets.

\section{The model}

We consider an incumbent firm acting as a monopolist for his product and facing an inverse demand curve $p^{F}(q, K)$, where $q$ denotes output quantity and $K$ is the knowledge stock of the firm determining the quality of the product. We make the following (standard) assumptions concerning $p$ :

$$
\frac{\partial p^{F}}{\partial q}<0, \quad \frac{\partial p^{F}}{\partial K}>0, \quad \frac{\partial^{2} p^{F}}{\partial q \partial K} \geq 0, \quad \frac{\partial^{2} p^{F}}{\partial K^{2}}<0 .
$$

Furthermore, we assume that for any given quantity $q$ the price $p^{F}(q, K)$ exhibits constant elasticity with respect to $K$. Marginal costs of production are normalized to zero. The profit of the firm when it produces the optimal quantity is denoted by $\pi^{F}(K)$. In order to build the knowledge stock $K$, the firm has to make the investment $I(K)$ in $\mathrm{R} \& \mathrm{D}$, with $I^{\prime}(K)>0$ and $I^{\prime \prime}(K)>0$ for $K \geq 0$. The knowledge stock is embodied in a key R\&D employee of the firm, and it is assumed to be partly tacit. In case the employee leaves the firm, only a fraction $\delta K$, with $0<\delta<1$, of the generated knowledge is retained by the firm.

Upon leaving the firm, the R\&D employee might use her knowledge stock $K$ to found a start-up company. In order to do so, complementary assets are needed, which are provided by a third party who keeps a fraction $1-\gamma$ of the profits generated by the start-up. The parameter $\gamma \in(0,1)$ can therefore be interpreted as a proxy of the availability of complementary assets in the considered industry.

The more easily available complementary assets are, the lower the fraction of the start-up's profit accruing to the provider. The net profit of the former R\&D employee following start-up formation is given by

$$
J^{E}(K ; \gamma)=\gamma \pi^{S}(K)-C,
$$

where $\pi^{S}(K)$ denotes the profit of the start-up firm and $C$ are the costs borne to found the start-up, which include the opportunity costs of the former employee's wage income at her former employer. It is assumed that the inverse demand for a product offered by a start-up cannot be as clearly anticipated as that of a pre-existing firm and it is

we use this indicator as a proxy for the easiness of accessing complementary assets and founding a start-up. 
always below that of an incumbent who has the same knowledge stock $K$. In other words, having been in the market for longer gives an advantage to the incumbent. In particular, we assume that the start-up faces the stochastic inverse demand curve

$$
p^{S}(q, K)=\xi p^{F}(q, K)
$$

where $\xi$ is uniformly distributed in $[0, \bar{\xi}]$ with $\bar{\xi}<1$. This implies $\pi^{S}(K)=\xi \pi^{F}(K)$.

Furthermore, it is assumed that the effect of the entry of the start-up firm on the demand for the product of the incumbent is negligible, and therefore the profit of the incumbent firm after the formation of the start-up is given by $\pi^{F}(\delta K) .{ }^{4}$

The following timing of events is considered.

1. The incumbent invests in order to generate the knowledge stock $K$.

2. The key employee learns the realization of the stochastic variable $\xi$.

3. The employee leaves the incumbent and she forms a start-up if and only if $J^{E}(K ; \gamma)>0$. In this case, only a knowledge stock of $\delta K$ remains within the incumbent firm.

4. The incumbent and the start-up (if it has been founded) realize their profits.

The assumption that the key employee learns the exact value of $\xi$ in step 2., and therefore the exact form of the demand function he would face when founding a startup is quite strong. However, nothing in the analysis changes if we assume that the key employee just receives a signal about the demand and $\xi p^{F}(q, K)$ denotes the inverse demand curve expected by the employee after receiving this signal.

The incumbent firm $F$ chooses its R\&D investments in order to maximize its expected pay-off taking into account the possibility for the employee to leave the firm and form a start-up. Formally, the problem of the incumbent can be written as

$$
\max _{K \geq 0} J^{F}(K ; \gamma):=\left[\pi^{F}(K)(1-v(K ; \gamma))+\pi^{F}(\delta K) v(K ; \gamma)-I(K)\right]
$$

where $v(K ; \gamma)=\mathcal{P}\left(J^{E}(K ; \gamma)>0\right)$ denotes the probability that a start-up firm is formed.

\footnotetext{
${ }^{4}$ Colombo and Dawid (2013) consider a setup where the incumbent and the start-up compete in a common market. The analysis carried out in that paper shows that the main qualitative insights obtained under the simplifying assumption made here extend to such a setting with more involved strategic interaction.
} 
In order to guarantee the concavity of the objective function in (2), we assume that the following inequality holds for all $K \geq 0$

$I^{\prime \prime}(K)>\pi^{F^{\prime \prime}}(K)(1-v(K ; \gamma))-2 \pi^{F^{\prime}}(K) v^{\prime}(K ; \gamma)+\delta^{2} \pi^{F^{\prime \prime}}(\delta K) v(K ; \gamma)+2 \delta \pi^{F^{\prime}}(\delta K) v^{\prime}(K ; \gamma)$

This condition requires that the marginal costs of producing knowledge grow sufficiently fast with $K$ to dominate any non-concavity of the expected market profit of the incumbent with respect to changes in the knowledge stock. It is also convenient to define with $\epsilon(K)=\frac{K \pi^{F^{\prime}}(K)}{\pi^{F}(K)}$ the elasticity of $\pi^{F}$ with respect to $K$. The dependence of this elasticity from the knowledge stock is characterized in the following Lemma.

Lemma 1 Under assumptions (1) the elasticity $\epsilon(K)$ is increasing with respect to $K$.

Proof. Taking into account that the firm is choosing the profit maximizing monopoly quantity $q^{m}(K)$ for each $K$, it follows from the envelope theorem that

$$
\pi^{F^{\prime}}(K)=\frac{\partial p^{F}\left(q^{m}(K), K\right)}{\partial K} q^{m}(K) .
$$

Hence,

$$
\epsilon(K)=\frac{1}{p^{F}\left(q^{m}(K), K\right)} K \frac{\partial p^{F}\left(q^{m}(K), K\right)}{\partial K} .
$$

Taking the derivative with respect to $K$ we obtain

$$
\begin{aligned}
\epsilon^{\prime}(K) & =\frac{1}{p^{F}\left(q^{m}(K), K\right)^{2}}\left[\left[\left(\frac{\partial^{2} p^{F}}{\partial K^{2}}+\frac{\partial^{2} p^{F}}{\partial K \partial q} \frac{\partial q^{m}(K)}{\partial K}\right) K+\frac{\partial p^{F}}{\partial K}\right] p^{F}+\right. \\
& \left.-K \frac{\partial p^{F}}{\partial K}\left(\frac{\partial p^{F}}{\partial K}+\frac{\partial p^{F}}{\partial q} \frac{\partial q^{m}(K)}{\partial K}\right)\right] \\
& =\frac{1}{p^{F}\left(q^{m}(K), K\right)^{2}} \underbrace{\left[\left(K \frac{\partial^{2} p^{F}}{\partial K^{2}}+\frac{\partial p^{F}}{\partial K}\right) p^{F}-K\left(\frac{\partial p^{F}}{\partial K}\right)^{2}\right]}_{=0(\text { due to constant elast. of } p)}+ \\
& +\frac{1}{p^{F}\left(q^{m}(K), K\right)^{2}}\left[\frac{\partial^{2} p^{F}}{\partial K \partial q} p^{F}-\frac{\partial p^{F}}{\partial K} \frac{\partial p^{F}}{\partial q}\right] K \frac{\partial q^{m}(K)}{\partial K} \\
& >0
\end{aligned}
$$

The last inequality follows from assumptions (1) and the observation that $\frac{\partial q^{m}(K)}{\partial K}>0$, which is implied by the assumption of constant elasticity of $p^{F}$ with respect to $K$.

The optimal solution of the maximization problem (2) is denoted by $K^{*}(\gamma)$. The following Proposition shows our main result, namely that the optimal investment in $\mathrm{R} \& \mathrm{D}$ of the incumbent firm decreases as complementary assets become more easily accessible. 
Proposition 1 Assume that (3) holds. Then, $K^{*}(\gamma)$ is decreasing in $\gamma$ for all $\gamma$ such that $K^{*}(\gamma)>0$.

Proof. Observe first that due to the global concavity of (2) for all $\gamma$ such that $K^{*}(\gamma)>0$ the optimal solution of the profit maximization problem is determined by the first order condition

$\pi^{F^{\prime}}(K)(1-v(K ; \gamma))-\pi^{F}(K) v^{\prime}(K ; \gamma)+\delta \pi^{F^{\prime}}(\delta K) v(K ; \gamma)+\delta \pi^{F}(\delta K) v^{\prime}(K ; \gamma)-I^{\prime}(K)=0$

Implicit differentiation of this condition with respect to $\gamma$ yields

$$
\frac{\partial K^{*}}{\partial \gamma}=-\frac{\frac{\partial^{2} J^{F}\left(K^{*} ; \gamma\right)}{\partial K \partial \gamma}}{\frac{\partial^{2} J^{F}\left(K^{*} ; \gamma\right)}{\partial K^{2}}},
$$

where $J^{F}(K ; \gamma)$ denotes the objective function of firm $F$ given in (2). Due to (3) we have $\frac{\partial^{2} J^{F}\left(K^{*} ; \gamma\right)}{\partial K^{2}}<0$ such that the sign of $\frac{\partial K^{*}}{\partial \gamma}$ is equal to that of $\frac{\partial^{2} J^{F}\left(K^{*} ; \gamma\right)}{\partial K \partial \gamma}$. Considering this expression, we get

$$
\frac{\partial^{2} J^{F}\left(K^{*} ; \gamma\right)}{\partial K \partial \gamma}=\frac{\partial v}{\partial \gamma}\left(\delta \pi^{F^{\prime}}(\delta K)-\pi^{F^{\prime}}(K)\right)+\frac{\partial^{2} v}{\partial \gamma \partial K}\left(\pi^{F}(\delta K)-\pi^{F}(K)\right) .
$$

Furthermore, since $\xi$ is assumed to be uniformly distributed, we have that

$$
v(K ; \gamma)=1-\frac{C}{\bar{\xi} \gamma \pi^{F}(K)},
$$

and therefore

$$
\begin{aligned}
\frac{\partial v}{\partial \gamma} & =\frac{C}{\bar{\xi} \gamma^{2} \pi^{F}(K)} \\
\frac{\partial^{2} v}{\partial \gamma \partial K} & =-\frac{C \pi^{F^{\prime}}(K)}{\bar{\xi} \gamma^{2} \pi^{F}(K)^{2}} .
\end{aligned}
$$

Overall, this gives

$$
\begin{aligned}
\frac{\partial^{2} J^{F}\left(K^{*} ; \gamma\right)}{\partial K \partial \gamma} & =\frac{C}{\bar{\xi} \gamma^{2} \pi^{F}(K)}\left[\delta \pi^{F^{\prime}}(\delta K)-\pi^{F^{\prime}}(K)-\frac{\pi^{F^{\prime}}(K)}{\pi^{F}(K)}\left(\pi^{F}(\delta K)-\pi^{F}(K)\right)\right] \\
& =\frac{C \pi^{F}(\delta K)}{K \bar{\xi} \gamma^{2} \pi^{F}(K)}\left[\frac{\delta K \pi^{F^{\prime}}(\delta K)}{\pi^{F}(\delta K)}-\frac{K \pi^{F^{\prime}}(K)}{\pi^{F}(K)}\right] \\
& =\frac{C \pi^{F}(\delta K)}{K \bar{\xi} \gamma^{2} \pi^{F}(K)}(\epsilon(\delta K)-\epsilon(K)) \\
& <0,
\end{aligned}
$$

where the last inequality follows from Lemma 1. 
To gain an economic intuition for this result it should be realized that the sign of the relationship between $K^{*}$ and $\gamma$ depends on the sign of the cross derivative of the incumbent's objective function with respect to $K^{*}$ and $\gamma$. The observation that $K^{*}$ is decreasing in $\gamma$ is equivalent to the statement that the marginal increase of the objective function given in (2) becomes smaller as $\gamma$ is increased. An increase of $\gamma$ has two effects on the derivative of $J^{F}$ with respect to $\gamma$. First, increasing $\gamma$ increases the probability $v(K ; \gamma)$ that a start-up is formed and, since the marginal return from additional R\&D investment for the incumbent is smaller if a start-up is formed compared to the case where the employee stays in the firm, this effect reduces $\frac{\partial J^{F}}{\partial K}$. The second effect is less straightforward. Increasing $\gamma$ affects also the size of the marginal effect of $K$ on the probability of start-up formation. Increasing $K$ makes the probability of start-up formation higher and this reduces the incentive of the incumbent to invest in $K$. If this disincentive is reduced by increasing $\gamma$ then this second effect would contribute to a positive relationship between $K^{*}$ and $\gamma$ and, if dominant, it could imply that $K^{*}(\gamma)$ is an increasing function. However, in Proposition 1 it is shown that under our assumptions the first direct effect is always dominant and therefore the incentives to invest in $R \& D$ decrease if the availability of complementary assets goes up.

\section{$3 \quad$ Data and key variables}

In order to empirically test the relevance of the result in Proposition 1 of Section 2, we use firm-level microdata drawn from the third Italian Community Innovation Survey (CIS), conducted over a three-year period (1998-2000) by the Italian National Institute of Statistics (ISTAT). ${ }^{5}$ This survey is representative of the entire population of Italian firms with more than 10 employees, at both the sector, regional and the firm size level. In more detail, the CIS 3 dataset adopts a weighting procedure that relates the sample of firms interviewed to the entire population (ISTAT, 2004). ${ }^{6}$ The dataset comprises

\footnotetext{
${ }^{5}$ CIS surveys are nowadays systematically collected every three-years in most European countries (as well as in extra-European countries, such as Korea). Surveys run in different periods slightly differ in the design of the questionnaire and/or in the disclosure policy of some of the variables .For our purposes, the CIS 3 survey is the more complete among the ones currently available. It is important to note that the different CIS surveys are conducted independently, with the only aim to be representative, with no attention to the longitudinal dimension of the data. Therefore, each survey is largely composed by different firms and no panel data are currently available.

${ }^{6}$ Firm selection is carried out through a "one step stratified sample design". The sample in each stratum is selected with equal probability and without reimmission. The stratification of the sample is based on the following three variables: firm size, sector, regional location. Technically, in the generic stratum $h$, the random selection of $n_{h}$ sample observations among the $N_{h}$ belonging to the entire population is realized through the following procedure: (i) a random number in the 0-1 interval
} 
a set of general information (industry of affiliation, group belonging, turnover, employment, exports) and a set of innovation variables measuring firms' innovativeness, subjective evaluations of factors hampering or fostering innovation, participation in cooperative innovation activities and access to public funding. The response rate was $53 \%$, determining a full sample size of 15,512 firms, both in manufacturing and service sectors.

As far as the focus of our paper is on innovative companies, we only keep firms declaring Research and Development expenditures (R\&D) greater than zero $(2,308$ companies). Furthermore, in order to identify incumbent and start-up firms in each industry, we use the 1994 year of foundation to discriminate between the two sub-groups (incumbent are identified as founded before 1994, young start-up companies as created in 1994 or afterwards). ${ }^{7}$ This step - due to missing values in the year of foundation slightly reduces the number of available observations to 2,124. Finally, as we assume that spin-offs are specific to a given industry and affected by sectoral complementary assets (see previous section), we use a rather detailed sectoral criterion in assigning firms to a given industry by adopting a three-digit industrial classification. ${ }^{8}$ To have a representative number of start-ups in each three-digit industrial sector, we exclude observations/industries with less than three start-ups. We end up with a sample of 1,721 innovate firms, of which 1,337 are incumbent and 384 young start-ups.

In order to empirically test the result of Proposition 1, we use the incumbent subsample as the $R \& D$ investors we are interested in, while the start-up sub-sample is used to get the information concerning the perception of the role of industrial complementary assets in affecting new firm formation based on innovation. Therefore, in the following econometric analysis, on the one hand we consider as dependent variable the $R \& D$ investments by the incumbent firms, normalized by sales in order to control for the is attributed to each $N_{h}$ population unit; (ii) $N_{h}$ population units are sorted by increasing values of the random number; (iii) units in the first $n_{h}$ positions in the order previously mentioned are selected. Estimates obtained from the selected sample are very close to the actual values in the national population. The weighting procedure follows the Eurostat and Oslo Manual (OECD, 1997) recommendations: weights indicate the inverse of the probability that the observation is sampled. Therefore, sampling weights ensure that each group of firms is properly represented and correct for sample selection. Moreover, they help reducing the heteroskedasticity commonly arising when the analysis focuses on survey data.

${ }^{7}$ As far as the age of the firms in the 'start-up' sub-sample is concerned, the 5 years threshold is chosen to solve the trade-off between a lower age and the representativeness of the sub-sample of young companies. With our selection procedure we end up with about $22 \%$ of the entire sample as start-ups.

${ }^{8}$ We use NACE rev.1.1 industrial classification and consider industrial three-digit disaggregation. Represented industries are reported in the Appendix, Table A1. 
scale effect due to the different size of the investigated firms. ${ }^{9}$ On the other hand, our main impact variable (the regressor representing the role of complementary assets in affecting the possible decision by an R\&D employee to use her knowledge to spin-off) is measured by the perception of young start-ups of the lack of financial sources as an obstacle to innovation. More in detail, this variable has been constructed on the basis of the question 12.3 of the Italian CIS 3 questionnaire, asking: "how important was the availability of finance as a constraint on innovation activities in influencing a decision not to innovate?" (rated on a Likert scale from 1 to $4 ; 1=$ high, $4=$ irrelevant/ not experienced). ${ }^{10}$

According to our model, if the availability of financial resources is not an obstacle for potential start-ups, R\&D employees easily spin-off from incumbent firms and incumbents - backwards - are not keen on investing in $\mathrm{R} \& \mathrm{D}$. Therefore, we expect a negative coefficient linking the availability of "complementary assets" (higher score of our impact variable) with incumbents' $R \& D$ investment.

CIS 3 provides further information on firms beyond their innovative activity. The following estimates adopt some of these indicators as further controls; in particular, we include four additional covariates in our specifications. The first accounts for a firm's access to policy support for innovation. A government subsidy or a fiscal incentive should increase a firm's innovative performance, although the empirical evidence on this is quite controversial, due to the possible insurgence of crowding out effects, displacing privately funded R\&D investments (see Wallsten, 2000; Gonzáles et Al., 2005; Catozzella and Vivarelli, 2012). The second controls for firms participating in a cooperation agreement for innovation. ${ }^{11}$ The third accounts for firms adopting organizational changes, which might create an encouraging environment in the company to make an innovation strategy more likely to be effective - especially in terms of the overall productivity performance of the company. ${ }^{12}$ The fourth control looks at a firm's export propensity. Global competition can spur innovation and capabilities,

\footnotetext{
${ }^{9}$ No information about the knowledge stock is available in the CIS database. However, this is not a problem within our model setting, where the R\&D investment $(I)$ is assumed to be positively correlated with the knowledge stock $(K)$. In fact, since $I^{\prime}(K)>0$, to empirically show that incumbents' R\&D investments and complementary assets $(\gamma)$ are inversely correlated is equivalent to prove the obtained result that the incumbents' knowledge stock is decreasing with respect to $\gamma$.

${ }^{10}$ As discussed in the Introduction, a variety of complementary assets may be needed to create a start-up, widely differing across industrial sectors. However, the availability of financial resources is the key factor in gaining access to those assets in all industries

${ }^{11}$ The important role of cooperation agreements in affecting the innovative output of firms is highlighted by Cassiman and Veugelers (2002), Piga and Vivarelli (2004), and Fritsch and Franke (2004).

${ }^{12}$ See Schmidt and Rammer (2007). On the complementarity between technological and organizational change, see Brynjolfsson and Hitt (2000), Bresnahan et Al. (2002), and Piva et Al. (2005).
} 
while technologically inactive firms are doomed to be excluded from the international arena (see Archibugi and Iammarino, 1999; Narula and Zanfei, 2003). Finally, our econometric specification includes the four Pavitt's sectoral dummies (Pavitt, 1984) plus a 'service-industries' dummy in order to control for the different sectoral technological opportunity and appropriability conditions (on the role of the so-called 'sectoral systems of innovation', see Malerba and Orsenigo, 1995; Breschi et Al., 2000).

Equation (4) describes the specification adopted for the empirical test.

$$
\begin{aligned}
& \log (R \& D / S A L E S)_{i}=C+\beta_{1} \text { Complementary Assets }_{i}+\beta_{2} \text { Support }_{i} \\
& +\beta_{3} \text { Cooperation }_{i}+\beta_{4} \text { Organizational Change }_{i}+ \\
& +\Sigma \beta_{5} \log (\text { Export/Sales })_{i}+\Sigma_{\gamma k} \text { Pavitt }_{k i}+\epsilon_{i},
\end{aligned}
$$

where $C$ is the constant, $i$ is the firm-index (incumbents), $\log (R \& D /$ Sales) represents the innovative investments intensity, Complementary Assets is computed on the evaluation of start-ups (in each three-digit industrial sector), Support, Cooperation, Organizational change and $\log (E X P O R T / S A L E S)$ (i.e.,export intensity) are the control variables previously discussed, and Pavitt are the sectoral dummies (sciencebased, scale-intensive, specialized-suppliers, services, with the suppliers-dominated firms as the default category; $k=4$ ). Note that, as it is common in the literature, continuous variables are log-transformed both to smooth heteroskedasticity problems and to mitigate the role of possible outliers.

\section{The evidence}

Table 1 describes the variables used in the empirical analysis and reports the corresponding descriptive statistics.

$<$ Insert Table 1: The variables - descriptive statistics about here >

The correlation matrix for the entire sample is reported in Table 2. As can be seen, all the correlation coefficients are less than 0.359 showing that data are not affected by serious collinearity problems.

<Insert Table 2: Correlation matrix about here> 
Table 3 reports the econometric results of the estimates run on the 1,337 incumbent firms. Diagnosis tests (F-test and R-squared) are satisfactory, taken into account the cross-sectional nature of the data. Moreover, the estimation has been controlled for both heteroskedasticity (using robust standard errors) and multicollinearity $(\mathrm{VIF}=1.36)$.

$<$ Insert Table 3: dependent variable: $\log (R \& D / S A L E S) ;$ observations $=1,337$ about here $>$

Our results show a negative and significant impact of the availability of complementary assets (evaluated by start-ups) upon incumbents' R\&D intensity, which lends considerable support to the theoretical claim of Proposition 1 in Section 2. Indeed, the correspondent coefficient shows the expected (negative) sign, a high level of significance (t-statistics equal to 2.33) and a considerable magnitude.

Turning our attention to the control variables, only the support for innovation turns out to positively affect $R \& D$ intensity, while the other controls do not reveal any significant impact.

Finally, focusing on the sectoral dummies and taking into account that the less innovative supplier-dominated firms are the reference category, not surprisingly sciencebased firms, followed by service companies and specialized suppliers, turn out to be more R\&D intensive (see the values and significance of the corresponding Pavitt's dummies).

\section{Concluding remarks}

Since innovation can be considered the main driver of economic growth, to investigate the factors that are fostering or hampering $R \& D$ investment is relevant. The theoretical model proposed in this paper claims that there is a strategic (negative) relationship between the availability of the complementary assets needed for the creation of a new firm and the innovative effort by incumbent firms. The evidence provided in the second part of the paper supports this theoretical prescription.

An important implication of our analysis is that the evaluation of policy measures aimed at reducing the barriers faced by potential start-up founders should not focus exclusively on the induced effects on the frequency of start-up formation and the subsequent success of these start-ups. Such an evaluation should also take into account the negative effects that these policies might have on the R\&D intensity of incumbents. 
Our theoretical and empirical results suggest that such negative effects exist across different sectors and regions. How large and relevant they are for different specific sectors and regions is an empirical issue open for future research.

Although the empirical results of this paper are consistent with the proposed theoretical model, our analysis is not immune from important limitations. First, both the theoretical model and the empirical specification focus exclusively on a strategic argument, while other factors may play a role, as discussed in Section 1. In this perspective, accounting for possible clustering and learning effects would be valuable extensions. Second, since complementary assets are specific to the single sectors, there is a need for a data collecting purposely addressed to catch and measure those assets, beyond the general availability of financial resources used in this paper. Third, the estimates in this study have a cross-sectional nature, while a dynamic specification would have allowed to properly compute the knowledge stock and to obtain more robust results; in this context, a need for longitudinal CIS data clearly emerges as a preliminary condition to extend the analysis through a dynamic test of the theoretical hypothesis proposed here.

\section{References}

Anand, B., Galetovic, A., 2000. Weak property rights and holdup in R\&D. Journal of Economics and Management Strategy 9, 615-642.

Anton, J., Yao, D., 1994. Expropriations and inventions: appropriable rents in the absence of property rights. American Economic Review 84, 190-209.

Anton, J., Yao, D., 1995. Start-ups, spin-offs, and internal projects. Journal of Law, Economics and Organization 11, 362-378.

Archibugi, D., Iammarino, S., 1999. The policy implications of the globalisation of innovation. Research Policy 28, 317-336.

Audretsch, D., Feldman, M., 1996. R\&D spillovers and the geography of innovation and production. American Economic Review 86, 630-640.

Breschi, Stefano, Malerba F., Orsenigo L., 2000. Technological regimes and Schumpeterian patterns of innovation. Economic Journal 110, 388-410.

Bresnahan, T.F., Brynjolfsson, E., Hitt, L.M., 2002. Information technology, workplace organization and the demand for skilled labor: firm-level evidence. Quarterly Journal of Economics 117, 339-376.

Brynjolfsson, E., Hitt, L.M., 2000. Beyond computation: information technology, organizational transformation and business performance. Journal of Economic Perspectives $14,23-48$. 
Cassiman, B., Veugelers, R., 2002. R\&D cooperation and spillovers: some empirical evidence from Belgium. American Economic Review 92, 1169-1184.

Catozzella, A., Vivarelli, M., 2012. The possible adverse impact of innovation subsidies: some evidence from a bivariate switching model. Economics Bulletin 32, $648-61$.

Colombo, L., Dawid, H., 2013. Complementary Assets, Start-Ups and Incentives to Innovate. Bielefeld Working Papers in Economics and Management No. 07-2013.

Colombo, L., Dawid, H., Kabus, K., 2012. When do thick venture capital markets foster innovation? An evolutionary analysis. Journal of Evolutionary Economics 22, 79-108.

Fallick, B., Fleischman, C., Rebitzer, J., 2006. Job-hopping in Silicon Valley: some evidence concerning the microfoundations of a high-technology cluster. Review of Economics and Statistics 88, 472-481.

Franco, A., Filson, D., 2006. Spin-outs: knowledge diffusion through employee mobility. RAND Journal of Economics 37, 841-860.

Fritsch, M., Franke, G., 2004. Innovation, regional knowledge spillovers and R\&D cooperation. Research Policy 33, 245-255.

Gersbach, H., Schmutzler, A., 2003a. Endogenous spillovers and incentives to innovate. Economic Theory 21, 59-79.

Gersbach, H., Schmutzler, A., 2003b. Endogenous technological spillovers: causes and consequences. Journal of Economics and Management Strategy 12, 179-205.

Gonzáles, X., Jaumandreu, J., Pazó, C., 2005. Barriers to innovation and subsidy effectiveness. RAND Journal of Economics 36, 930-949.

Hanson, G.H., 2001. Scale economies and the geographic concentration of industry. Journal of Economic Geography 1, 255-276.

Jaffe, A., Trajtenberg, M., Henderson, R., 1993. Geographic localization of knowledge spillovers as evidenced by patent citations. Quarterly Journal of Economics 108, $577-598$.

Klepper, S., 2010. The origin and growth of industry clusters: the making of Silicon Valley and Detroit. Journal of Urban Economics 67, 15-32.

Klepper, S., Sleeper S., 2005. Entry by spinoffs. Management Science 51, 12911306.

ISTAT, 2004. Statistiche sull'Innovazione delle Imprese. Settore Industria. Anni 1998-2000, Rome: ISTAT.

Malerba, F., Orsenigo, L., 1995. Schumpeterian patterns of innovation. Cambridge Journal of Economics 19, 47-65.

Narula, R., Zanfei, A., 2003. The international dimension of innovation. In J. 
Fagerberg, D.C. Mowery and R.R. Nelson, eds., The Oxford Handbook of Innovation. Oxford: Oxford University Press, 318-345.

OECD, 1997. Oslo Manual: The Measurement of Scientific and Technological Activities. Proposed Guideline for Collecting and Interpreting Technological Innovation Data. Paris: OECD.

Park, H., and H. Steensma, 2012. When does corporate venture capital add value for new ventures?. Strategic Management Journal, 33, 1-22.

Pavitt, K., 1984. Sectoral patterns of technical change: towards a taxonomy and a theory. Research Policy 13, 343-373.

Piga, C.A., Vivarelli, M., 2004. Internal and external R\&D: a sample selection approach. Oxford Bulletin of Economics and Statistics 66, 457-482.

Piva, M., Santarelli, E., Vivarelli, M. 2005. The skill bias effect of technological and organisational change: evidence and policy implications. Research Policy 34, 141-157.

Rothaermel, F., Hill, C., 2005. Technological discontinuities and complementary assets: a longitudinal study of industry and firm performance. Organization Science $16,50-70$.

Schmidt, T., Rammer, C., 2007. Non-technological and technological innovation: strange bedfellows? ZEW Discussion Paper No. 07-052.

Spulber, D., 2012. Tacit knowledge with innovative entrepreneurship. International Journal of Industrial Organization 30, 641-653.

Teece, D. 1986. Profiting from technological innovation: implications for integration, collaboration, licensing and public policy. Research Policy, 15, 285-305.

Wallsten, S.J., 2000. The effects of government-industry R\&D programs on private R\&D: the case of the Small Business Innovation Research Program. RAND Journal of Economics 31, 82-100.

Zucker, L., Darby, M., Brewer, M., 1998. Intellectual human capital and the birth of U.S. biotechnology enterprises. American Economic Review 88, 290-306.

\section{Appendix}

$<$ Table A1: Three-digit sectoral classification - Incumbents and start-ups> 
Table 1: The variables - descriptive statistics

\begin{tabular}{|l|c|c|}
\hline & Mean & $\begin{array}{c}\text { Standard } \\
\text { Deviation }\end{array}$ \\
\hline R\&D investment normalized by sales (year 2000) & 0.028 & 0.058 \\
\hline $\begin{array}{l}\text { COMPLEMENTARY ASSETS = Likert-scale: 1 (lack of financial } \\
\text { resource is a serious problem) to 4 (lack of financial resource is not } \\
\text { an issue), as evaluated by young start-up firms }\end{array}$ & 2.928 & 0.473 \\
\hline $\begin{array}{l}\text { SUPPORT Dummy = 1 if the firm has received public support for } \\
\text { innovation }\end{array}$ & 0.554 & 0.497 \\
\hline $\begin{array}{l}\text { COOPERATION Dummy =1 if the firm takes part into } \\
\text { cooperative innovative activities }\end{array}$ & 0.249 & 0.433 \\
\hline $\begin{array}{l}\text { ORGANIZATIONAL CHANGE Dummy =1 if the firm has } \\
\text { introduced organizational changes }\end{array}$ & 0.689 & 0.462 \\
\hline EXPORT normalized by sales (year 2000) & 0.278 & 0.292 \\
\hline Pavitt sectoral dummies & 0.185 & 0.388 \\
\hline SB Dummy = 1 if science-based firm & 0.137 & 0.344 \\
\hline SI Dummy = 1 if scale intensive firm & 0.350 & 0.477 \\
\hline SS Dummy = 1 if specialized supplier firm & 0.192 & 0.322 \\
\hline SD Dummy = 1 if supplier-dominated firm & 0.136 & 0.343 \\
\hline SER Dummy = 1 if firm in service industries & & \\
\hline
\end{tabular}

Table 2: Correlation matrix

\begin{tabular}{|c|c|c|c|c|c|c|c|c|c|}
\hline & 点至 & 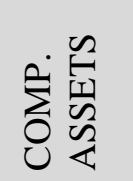 & 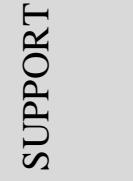 & $\begin{array}{l}\text { oิ } \\
\text { o }\end{array}$ & ن & 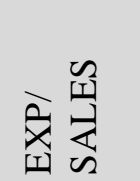 & $\bar{\omega}$ & $n$ & $\stackrel{n}{\omega}$ \\
\hline COMP.ASSETS & $-0.108 *$ & & & & & & & & \\
\hline SUPPORT & $0.122^{*}$ & $-0.066^{*}$ & & & & & & & \\
\hline COOP. & $0.113^{*}$ & -0.041 & $0.177^{*}$ & & & & & & \\
\hline ORG.CHANGE & 0.012 & 0.022 & 0.026 & $0.103^{*}$ & & & & & \\
\hline EXP/SALES & 0.040 & $0.071 *$ & $0.072 *$ & 0.007 & 0.028 & & & & \\
\hline SI & $-0.086 *$ & 0.043 & $\begin{array}{l}-0.037 \\
\end{array}$ & $-0.064 *$ & 0.008 & -0.021 & & & \\
\hline SS & $-0.118 *$ & $0.183^{*}$ & 0.024 & $-0.061^{*}$ & -0.006 & $0.071 *$ & $-0.292 *$ & & \\
\hline SB & $0.100^{*}$ & $-0.359^{*}$ & $0.066^{*}$ & $0.130^{*}$ & 0.028 & -0.000 & $-0.189 *$ & $-0.349 *$ & \\
\hline SER & $0.269 *$ & -0.025 & $-0.064^{*}$ & $0.093^{*}$ & $0.059 *$ & $-0.054^{*}$ & $-0.158^{*}$ & $-0.291 *$ & $-0.189 *$ \\
\hline
\end{tabular}

Note: * significant at 5\%, 
Table 3: dependent variable: $\log (\mathrm{R} \& D / \mathrm{SALES}) ;$ observations $=1,337$

\begin{tabular}{|l|l|}
\hline \multicolumn{2}{|l|}{} \\
\hline CONSTANT & $\begin{array}{l}-4.581^{* * *} \\
(0.334)\end{array}$ \\
\hline \multirow{2}{*}{ COMPLEMENTARY ASSETS } & $-0.245^{* *}$ \\
& $(0.105)$ \\
\hline \multirow{2}{*}{ SUPPORT } & $0.705^{* * *}$ \\
& $(0.080)$ \\
\hline \multirow{2}{*}{ COOPERATION } & -0.037 \\
& $(0.099)$ \\
\hline ORGANIZATIONAL CHANGE & -0.108 \\
& $(0.081)$ \\
\hline \multirow{2}{*}{ Log(EXPORT/SALES) } & -0.261 \\
& $(0.240)$ \\
\hline SB & $1.063^{* * *}$ \\
& $(0.131)$ \\
\hline SI & 0.147 \\
& $(0.130)$ \\
\hline SS & $0.513^{* * *}$ \\
& $(0.102)$ \\
\hline SER & $0.641^{* * *}$ \\
\hline & $(0.190)$ \\
\hline F(9, 1327) & \\
\hline R 2 & $23.49^{* * *}$ \\
\hline
\end{tabular}

Notes: - Robust standard errors in brackets: * significant at 10\%, ** significant at $5 \%$, *** significant at $1 \%$ - No multicollinearity problems have been detected 
Table A1: Three-digit sectoral classification - Incumbents and start-ups

\begin{tabular}{|c|c|c|c|c|c|c|}
\hline NACE Rev.1.1 & & CUMBI & ENTS & & TART & -UPS \\
\hline & Code & Freq. & Percent & Code & Freq. & Percent \\
\hline - Manufacturing of other food prods; & 158 & 31 & 2.32 & 158 & 10 & 2.60 \\
\hline - Manufacturing of other textiles; & 175 & 12 & 0.90 & 175 & 3 & 0.78 \\
\hline - Manufacturing of knitted articles; & $177 \mid$ & 11 & 0.82 & 177 & 4 & 1.04 \\
\hline - Manufacturing of other wearing app.; & 182 & 20 & 1.50 & 182 & 5 & 1.30 \\
\hline - Manufacturing of basic chemicals; & $241 \mid$ & 33 & 2.47 & 241 & 13 & 3.39 \\
\hline - Manufacturing of paints, varnishes; & 243 & 33 & 2.47 & 243 & 4 & 1.04 \\
\hline - Manufacturing of pharmaceuticals; & 244 & 61 & 4.56 & 244 & 6 & 1.56 \\
\hline - Manufacturing of soap; & 245 & 20 & 1.50 & 245 & 6 & 1.56 \\
\hline - Manufacturing of other chemicals; & 246 & 23 & 1.72 & 246 & 9 & 2.34 \\
\hline - Manufacturing of rubber products; & 251 & 15 & 1.12 & 251 & 4 & 1.04 \\
\hline - Other first processing of iron; & 273 & 11 & 0.82 & 273 & 6 & 1.56 \\
\hline - Manufacturing of non-ferrous metals; & 274 & 7 & 0.52 & 274 & 3 & 0.78 \\
\hline - Manufacturing of metal prods; & 281 & 13 & 0.97 & 281 & 5 & 1.30 \\
\hline - Treatment and coating of metals; & 285 & 13 & 0.97 & 285 & 6 & 1.56 \\
\hline - Manufacturing of other metal prods; & 287 & 31 & 2.32 & 287 & 7 & 1.82 \\
\hline - Manufacturing of machinery; & 291 & 46 & 3.44 & 291 & 10 & 2.60 \\
\hline - Manufacturing of other gen. p. mach.; & 292 & 57 & 4.26 & 292 & 12 & 3.13 \\
\hline - Manufacturing of machinetools; & 294 & 18 & 1.35 & 294 & 5 & 1.30 \\
\hline - Manufacturing of special p. mach.; & 295 & 75 & 5.61 & 295 & 19 & 4.95 \\
\hline - Manufacturing of office machinery; & $300 \mid$ & 29 & 2.17 & 300 & 12 & 3.13 \\
\hline - Manufacturing of electric motors; & 311 & 30 & 2.24 & 311 & 8 & 2.08 \\
\hline - Manufacturing of electricity distrib.; & 312 & 27 & 2.02 & 312 & 3 & 0.78 \\
\hline - Manufacturing of insulated cable; & 313 & 8 & 0.60 & 313 & 3 & 0.78 \\
\hline - Manufacturing of parts motor vehi.; & 343 & 33 & 2.47 & 343 & 9 & 2.34 \\
\hline - Building and repairing of ships; & $351 \mid$ & 5 & 0.37 & $351 \mid$ & 4 & 1.04 \\
\hline - Manufacturing of motorcycles; & 354 & 17 & 1.27 & 354 & 4 & 1.04 \\
\hline - Manufacturing of furniture; & $361 \mid$ & 42 & 3.14 & 361 & 5 & 1.30 \\
\hline - Manufacturing of gas; & 402 & 4 & 0.30 & 402 & 3 & 0.78 \\
\hline - Wholesale of household goods; & 514 & 9 & 0.66 & 514 & 3 & 0.78 \\
\hline - Wholesale of machinery; & 518 & 9 & 0.66 & 518 & 3 & 0.78 \\
\hline - Other supporting transport act.s; & 632 & 6 & 0.44 & 632 & 3 & 0.78 \\
\hline - Activities of travel agencies; & $633 \mid$ & 3 & 0.22 & $633 \mid$ & 5 & 1.30 \\
\hline - Monetary intermediation; & $651 \mid$ & 24 & 1.80 & $651 \mid$ & 16 & 4.16 \\
\hline - Software consultancy and supply; & 722 & 55 & 4.11 & 722 & 27 & 7.03 \\
\hline - Data processing; & 723 & 8 & 0.60 & 723 & 3 & 0.78 \\
\hline - Other computer related activities; & 726 & 2 & 0.15 & 726 & 5 & 1.30 \\
\hline - Research on natural sciences; & 731 & 18 & 1.35 & 731 & 8 & 2.08 \\
\hline - Legal,accounting,auditing activities; & $741 \mid$ & 5 & 0.37 & $741 \mid$ & 4 & 1.04 \\
\hline - Architectural/engineering activities; & 742 & 31 & 2.32 & 742 & 12 & 3.13 \\
\hline \multirow[t]{2}{*}{ - Technical testing and analysis; } & $743 \mid$ & 12 & 0.90 & 743 & 8 & 2.08 \\
\hline & Tota & 1,337 & 100.00 & Total | & 384 & 100.00 \\
\hline
\end{tabular}

